\title{
Decorin Suppresses Tumor Cell Growth by Activating the Epidermal Growth Factor Receptor
}

\author{
David K. Moscatello, ${ }^{\star}$ Manoranjan Santra, ${ }^{\ddagger}$ David M. Mann, ${ }^{\S} \|$ David J. McQuillan, ${ }^{\mathbb{1}}$ Albert J. Wong, ${ }^{*}$ and Renato V. lozzo ${ }^{\ddagger}$ \\ *Department of Microbiology and Immunology, ${ }^{*}$ Department of Pathology, Anatomy and Cell Biology, and the Kimmel Cancer Center, \\ Jefferson Medical College, Thomas Jefferson University, Philadelphia, Pennsylvania 19107; ${ }^{\S}$ Holland Laboratories, American Red Cross,

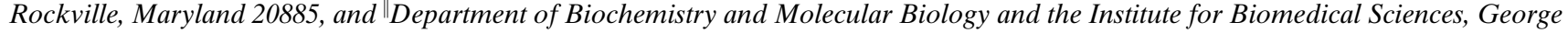 \\ Washington University Medical Center, Washington, DC 20003; and ${ }^{\mathbb{I} C e n t e r ~ f o r ~ E x t r a c e l l u l a r ~ M a t r i x ~ B i o l o g y, ~ I n s t i t u t e ~ o f ~ B i o s c i e n c e s ~ a n d ~}$ \\ Technology, Texas A\&M University, Houston, Texas 77030
}

\begin{abstract}
Decorin, a small leucine-rich proteoglycan, is capable of suppressing the growth of various tumor cell lines when expressed ectopically. In this report, we investigated the biochemical mechanism by which decorin inhibits cell cycle progression. In A431 squamous carcinoma cells, decorin proteoglycan or protein core induced a marked growth suppression, when either exogenously added or endogenously produced by a transgene. Decorin caused rapid phosphorylation of the EGF receptor and a concurrent activation of mitogen-activated protein (MAP) kinase signal pathway. This led to a protracted induction of endogenous p21, a potent inhibitor of cyclin-dependent kinases, and ultimate cell cycle arrest. Biglycan, a related proteoglycan, had no effect. Moreover, decorin activated the EGF receptor/MAP kinase/ p21 axis in cell lines of various histogenetic backgrounds. These results provide the first evidence that EGF and decorin converge functionally to regulate the cell cycle through activation of a common pathway which ultimately leads to growth suppression. (J. Clin. Invest. 1998. 101:406-412.) Key words: proteoglycans - biglycan - cell proliferation MAP kinase $\bullet$ p21
\end{abstract}

\section{Introduction}

The control of cell proliferation is a central event in tumorigenesis and often depends on the interactions between growth factors and their specific receptor-activated signaling pathways. Current views indicate that the nature of the local extracellular matrix can modulate cellular responses to a given signal in several manners, for example by affecting the affinity of the ligand for its cognate receptor or by influencing proteolytic processing and internalization (1). Decorin (2-4), the prototype member of an expanding family of small leucine-rich proteoglycans (5), is an important regulator of matrix assembly

Address correspondence to Renato V. Iozzo, Department of Pathology, Anatomy and Cell Biology, Room 249, Jefferson Alumni Hall, Thomas Jefferson University, 1020 Locust Street, Philadelphia, PA 19107. Phone: 215-503-2208; FAX: 215-923-7969; E-mail: Iozzo@lac. jci.tju.edu

Received for publication 7 June 1997 and accepted in revised form 19 November 1997.

J. Clin. Invest.

(C) The American Society for Clinical Investigation, Inc. 0021-9738/98/01/0406/07 \$2.00

Volume 101, Number 2, January 1998, 406-412

http://www.jci.org primarily because of its ability to bind collagen type I and to delay fibrillogenesis in vitro $(6,7)$. This function has been confirmed in mice harboring a targeted disruption of both decorin alleles. In these animals, lack of decorin leads to abnormal collagen fiber formation and a phenotype typified by skin thinning and fragility (8). Decorin content is markedly increased in the tumor stroma of colon cancer (9) and ectopic expression of decorin inhibits cell growth and prevents fibrosis by blocking TGF- $\beta$ activity $(10,11)$. These growth-suppressive properties of decorin are supported by a number of observations including: (a) decorin levels are markedly elevated during quiescence; $(b)$ decorin is rarely expressed by actively proliferating or transformed cells; $(c)$ decorin expression is abrogated by viral transformation; and $(d)$ decorin gene transcription is suppressed in a variety of tumorigenic cell lines and tumor tissues by methylation of its control regions (5). When colon carcinoma cells were stably transfected with a decorin-expressing vector, the cells became quiescent, with $\sim 90 \%$ of the cells arrested in the $G_{1}$ phase of the cell cycle, lost their malignant phenotype (12) and exhibited a marked upregulation of endogenous $\mathrm{p} 21^{\text {Wafl/Cip } 1 / \text { Sdil }}(\mathrm{p} 21)^{1}(13)$, a potent inhibitor of cyclin-dependent kinase (CDK) activity $(14,15)$ that is also induced at senescence (16). The augmented p21 protein was present in a multimeric complex with various cyclins and CDKs in the nuclei of the decorin-expressing clones and its levels could be abolished by abrogating decorin expression (13). Ectopic expression of decorin suppresses growth not only of colon carcinoma cells, but also that of neoplastic cells with a diverse histogenetic background, including tumor cells derived from genitourinary, skeletal, cutaneous, and bone marrow tissues (17). The growth-suppressive properties of decorin are independent of a functional p53 or retinoblastoma protein but require a functional p21 insofar as p21-deficient colon carcinoma cells (18) are totally unresponsive to the action of decorin (17).

The purpose of this study is to identify the signal transducing pathway through which decorin may mediate its growthsuppressive activity. We discovered that decorin activated the EGF receptor in A431 squamous carcinoma cells and in several transformed cell lines. This signaling was mediated by the protein core of decorin and induced MAP kinase activation and a protracted induction of endogenous $\mathrm{p} 21$, thereby leading to growth suppression. These results provide a biochemical mechanism for the growth-suppressive properties of decorin and indicate that the upregulation of decorin gene expression

1. Abbreviations used in this paper: $\mathrm{CDK}$, cyclin-dependent kinase; $\Delta$ decorin, a mutated form of decorin lacking the glycosaminoglycan side chain; MAP, mitogen-activated protein; $\mathrm{p} 21$, the CDK inhibitor also known as $\mathrm{p} 21^{\text {Wafl//Cip } 1 / \text { Sdil }}$. 
around neoplastic cells may represent a defensive mechanism of the tumor stroma designed to counterbalance the invasive tumor cells.

\section{Methods}

Cell lines, stable transfection, Northern and Western immunoblotting. The A431 squamous carcinoma and NIH3T3 fibroblasts were purchased from ATCC (Rockville, MD). The HNCC carcinoma cells were obtained from K. Somers (Eastern Virginia Medical School, Norfolk, VA). The other cell lines, including Saos-2 osteosarcoma, HT1080 fibrosarcoma, and HeLa cervical squamous carcinoma cells were described before (17). Stable transfection of A431 cells with either decorin or $\Delta$ decorin, a mutated cDNA lacking the glycosaminoglycan attachment site, cell proliferation assays, Northern and Western blottings were performed as previously described (12). Stable transfection with a full-length EGF receptor cDNA of the NIH3T3 fibroblasts and immunoprecipitation studies were done as described before (19). The antiphosphotyrosine monoclonal antibody PY20 was from Transduction Laboratories (Lexington, KY), the anti-EGF receptor monoclonal antibody was from Promega Corp. (Madison, WI), and the mouse monoclonal 6B6 antibody directed toward human p21 was from PharMingen (San Diego, CA). Quantification of immunoblots was performed with a PhosphorImager 445SI (Molecular Dynamics, Sunnyvale, CA).

Recombinant decorin and its biological effects. Decorin was purified from the secretions of Chinese hamster ovary $(\mathrm{CHO})$ cells transfected with a full length decorin-expressing vector (20) as described before (17). In addition, we utilized recombinant decorin proteoglycan, decorin protein core, or biglycan proteoglycan purified from HT1080 fibrosarcoma cells infected with a recombinant vaccinia virus $(21,22)$. All the recombinant preparations tested for biological activity contained undenatured protein cores, and the final products were assessed for purity by SDS-PAGE and immunoblotting. Routinely, cells were serum starved overnight and lysed without stimulation, or after treatment with either $50-100 \mu \mathrm{g} / \mathrm{ml}$ decorin, decorin protein core, or biglycan, or with $100 \mathrm{ng} / \mathrm{ml}$ EGF. Cell lysates were subjected to immunoprecipitation with either $\alpha$ pTyr or $\alpha$ EGFR antibodies, followed by separation by SDS-PAGE and immunoblotting with the antisera described above. The CellTiter $96^{\mathrm{TM}}$ Aqueous Non-Radioactive Cell Proliferation Assay (Promega Corp.) was used to determine the number of viable cells in a proliferative phase. Decorin was labeled with [ $\left.{ }^{125} \mathrm{I}\right] \mathrm{NaI}$ (Amersham Corp., Arlington Heights, IL) to a specific activity of $\sim 8 \times 10^{6} \mathrm{cpm} / \mu \mathrm{g}$ using the Iodo-Gen method (Pierce Chemical Co., Rockford, IL) according to the manufacturer's protocol. A431 cells were plated in 16-mm wells, grown for $2 \mathrm{~d}$ to near confluence, washed twice with D-PBS, and the wells were blocked with $1 \mathrm{ml}$ RPMI-1640 containing $0.2 \%$ BSA at $4^{\circ} \mathrm{C}$ for $1 \mathrm{~h}$. The medium was removed, and the cells were incubated in $0.5-\mathrm{ml}$ $0.2 \%$ BSA/RPMI-1640 containing $200 \mathrm{ng}\left(1.5 \times 10^{6} \mathrm{cpm}\right){ }^{125}$ I-labeled decorin \pm various concentrations of EGF. After $2 \mathrm{~h}$ on ice, the wells were washed three times with cold PBS, the cells were dissolved in $1 \mathrm{ml} /$ well $1 \mathrm{M} \mathrm{NaOH}$ and the radioactivity measured in a gamma counter. The $P$ values were determined using the paired Student's $t$ test. Additional experimental details are provided in the text and legends to figures.

\section{Results}

Ectopic expression of decorin proteoglycan or protein core causes growth suppression in A431 cells via activation of endogenous $p 21$. Because the most pronounced decorin-induced growth suppression occurred in epithelial-derived tumors, we hypothesized that the EGF receptor might be involved in this process. EGF can be stimulatory in several normal and malignant cells, but the proliferation of certain cells is inhibited by

\section{A}
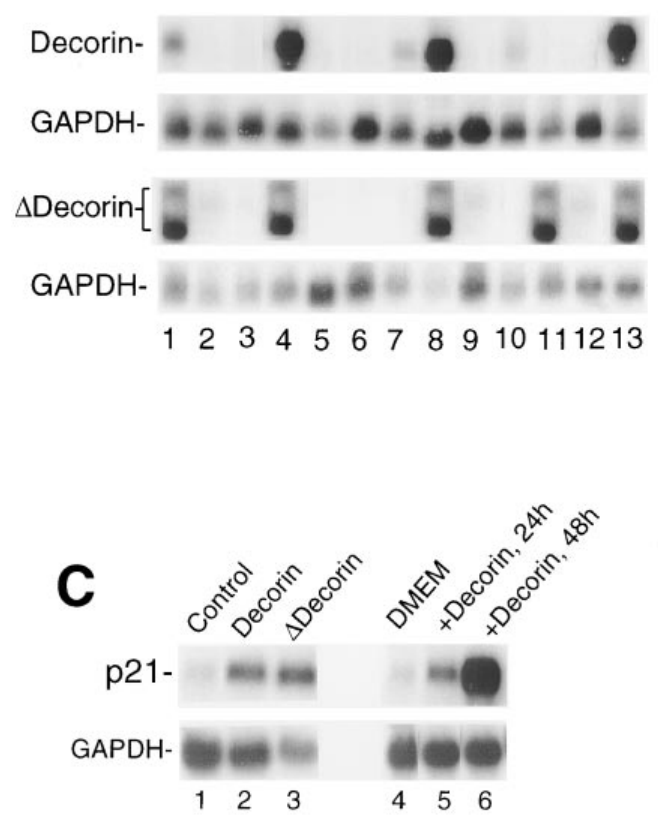

B
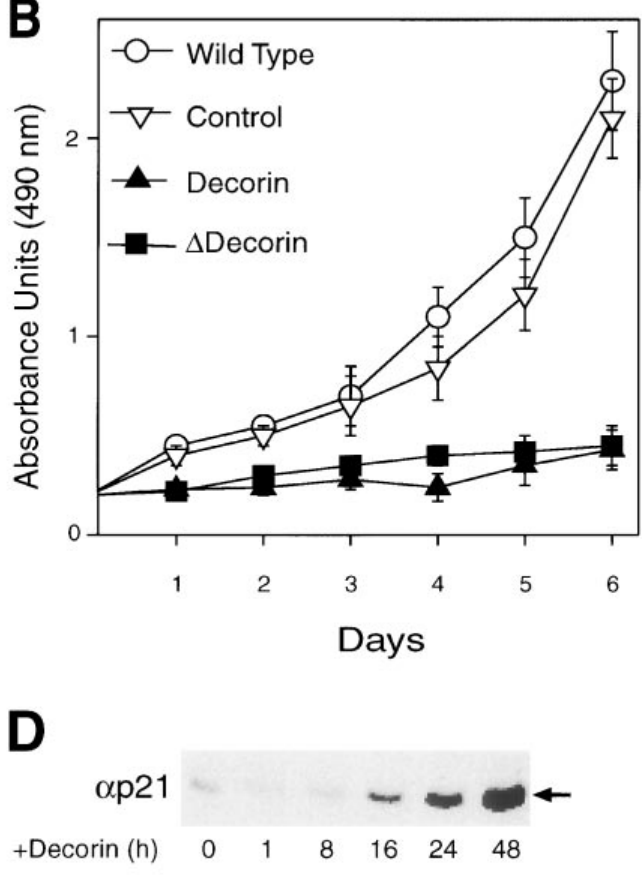

Figure 1. Ectopic expression of decorin proteoglycan or protein core induces marked growth suppression in A431 squamous carcinoma cells via activation of $\mathrm{p} 21 .(A)$ Representative Northern blotting analyses of transfected clones of A431 stably expressing either decorin proteoglycan or a mutated form of decorin (Adecorin) lacking any glycosaminoglycan side chain (lanes 1-13). The blots were normalized to GAPDH. Note that clones used for detailed studies were selected solely on decorin expression. (B) Growth curves of decorin-transfected clones as determined by a nonradioactive cell proliferation assay (12). Similar inhibitory effects were

observed with various clones expressing decorin or $\Delta$ decorin. $(C)$ Northern blotting analysis using human p21 cDNA as labeled probe of permanent transfected clones including cells transfected with vector alone (lane 1), decorin-expressing cells (lane 2), or cells expressing $\Delta$ decorin (lane 3). The right panel derives from parental A431 cells exposed for $24 \mathrm{~h}$ to medium alone (lane 4 ) or to $100 \mu \mathrm{g} / \mathrm{ml}$ of either decorin proteoglycan (lane 5) or $\Delta$ decorin (lane 6). (D) Immunoblot detection of $\mathrm{p} 21$ protein levels in A431 cells treated for various periods of time with recombinant human decorin $(100 \mu \mathrm{g} / \mathrm{ml})$. 
this growth factor (23). Thus, we tested A431 human squamous carcinoma cells, because these cells express a high number of EGF receptors $\left(\sim 2 \times 10^{6} /\right.$ cell $)$ and because their growth is suppressed by exogenous EGF (24). Stable transfection with either full length decorin or a mutated form of decorin ( $\Delta$ decorin) lacking any glycosaminoglycan side chain (Fig. $1 A$ ) induced a marked and protracted growth suppression (Fig. $1 B$ ) and a concurrent induction of p21 mRNA (Fig. 1C). A significant induction of endogenous p21 mRNA levels was also obtained when wild-type A431 cells were cultured in the presence of highly purified human recombinant decorin isolated from either HT-1080 fibrosarcoma cells (22) (Fig. 1C) or $\mathrm{CHO}$ cells (not shown). The kinetics of growth inhibition were consistent with the time course induction of $\mathrm{p} 21$ protein by exogenous decorin (Fig. $1 D$ ).

Exogenous decorin or decorin protein core, but not biglycan, causes growth suppression and p21 induction. The specificity of the growth suppression was further tested in experiments in which A431 cells were incubated in the presence or absence of decorin, its core protein or biglycan, a related proteoglycan (5). The results showed that the core protein of decorin was capable of inducing a protracted growth suppression (Fig. $2 A$ ) and a concurrent induction of endogenous p21 (Fig. $2 \mathrm{~B}$ ), whereas equimolar amounts of recombinant bigly-

A

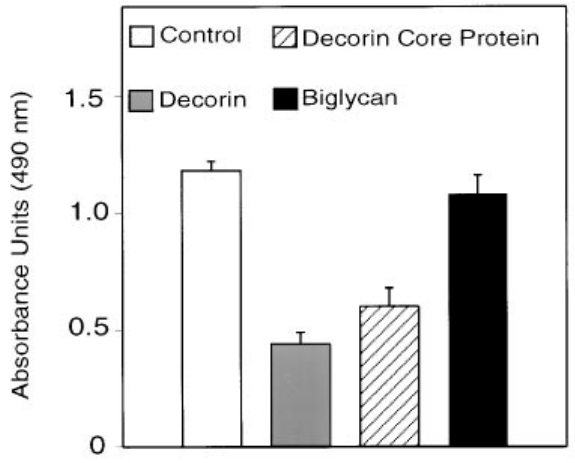

B

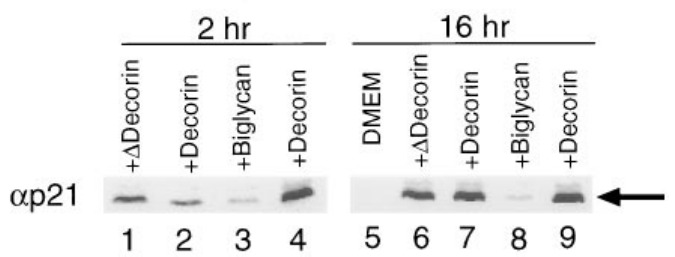

Figure 2. Exogenous decorin or decorin protein core, but not biglycan, causes growth suppression and induction of endogenous p21. $(A)$ Growth effects of exogenous human recombinant decorin, decorin protein core, or biglycan on the growth of wild-type A431 cells. The recombinant proteins $(100 \mu \mathrm{g} / \mathrm{ml}=\sim 1 \mu \mathrm{M})$ were added daily for $3 \mathrm{~d}$ and growth was assessed by a nonradioactive cell proliferation assay. (B) Immunoblot detection of $\mathrm{p} 21$ protein levels in A431 cells treated for 2 or $16 \mathrm{~h}$ (as indicated) with recombinant human decorin protein core ( $\Delta$ decorin $)$, decorin or biglycan proteoglycan $(100 \mu \mathrm{g} / \mathrm{ml}$ each $)$ synthesized by HT-1080 fibrosarcoma cells. The decorin in lanes 4 and 9 was derived from $\mathrm{CHO}$ cells. can were essentially ineffective. Similar results were obtained with a different preparation of human recombinant decorin synthesized by $\mathrm{CHO}$ cells (not shown) and required at least $24 \mathrm{~h}$ to be noticeable. Of note, a fusion protein containing decorin and the maltose binding protein produced in Escherichia coli was totally ineffective in inducing growth suppression (not shown). Collectively, these findings indicate that the growth suppression in A431 cells is specifically mediated by the protein core of decorin. Morever, our data indicate that this effect requires proper protein folding for full biological activity since the inactive prokaryotic form of decorin presumably lacks disulfide bonds (22) at both the amino and carboxyl ends of the molecule.

Decorin induces phosphorylation of the EGF receptor and concomitant MAP kinase activation in A431 cells. We next wanted to test whether EGF receptor itself mediated the decorin-induced growth suppression. The EGF receptor is a transmembrane glycoprotein with an extracellular ligand-binding domain and an intracellular tyrosine kinase domain whose ac-

A

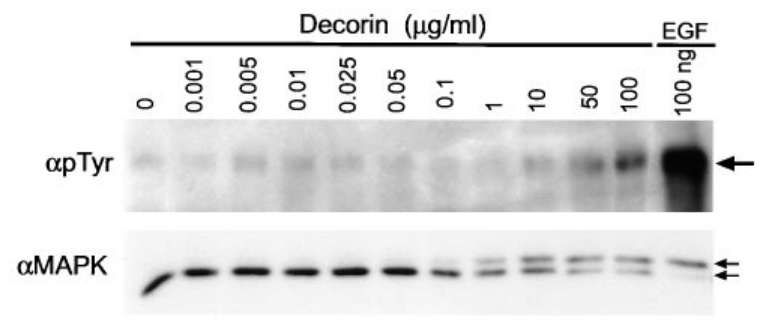

B

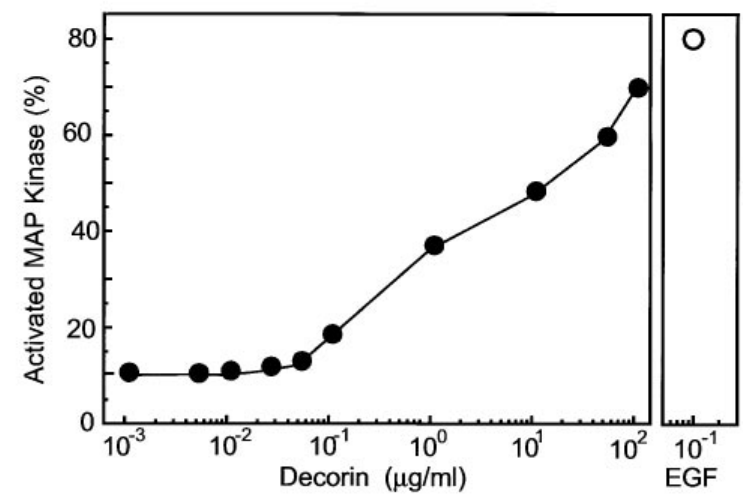

Figure 3. Decorin induces phosphorylation of EGF receptor and concomitant MAP kinase activation in wild-type A431 cells. $(A)$ EGF receptor tyrosine phosphorylation induced by exposure to the indicated amounts of decorin for 5 min before lysis (large arrow). EGF $(100 \mathrm{ng} / \mathrm{ml})$ was used as positive control. The immunoblots were probed with an antiphosphotyrosine antiserum ( $\alpha p T y r)$ (19). The lower panel shows immunoblotting analysis of the same cell lysates using an antiserum directed toward ERK1/ERK2 MAP kinases $(\alpha M A P K)$. Notice the activation of p42 ERK2 as manifested by the appearance of a slower-moving isoform (upper small arrow). (B) Quantification of the decorin-induced ERK2 activation as related to that induced by EGF. The MAP kinase bands in each lane of the lower panel in $A$ were quantified with the PhosphorImager, and the percentage of total MAP kinase in the activated form ([pp42/(pp42+ $\mathrm{p} 42)] \times 100 \%$ ) was plotted against the concentration of exogenous decorin. Open symbol in right panel shows the percent activated MAP kinase induced by a 5-min exposure to $100 \mathrm{ng} / \mathrm{ml} \mathrm{EGF}$. 
tivity is induced by EGF (25). The tyrosine-phosphorylated EGF receptor binds to modular signal proteins and eventually leads to activation of MAP kinases ERK1 and ERK2, two members of a network of highly conserved enzymes involved in responses to extracellular signals (26). Phosphorylation of both threonine and tyrosine residues in a $\mathrm{T} \times \mathrm{Y}$ sequence common to most MAP kinases is required for their full activation (26) and this phosphorylation can be detected as a shift toward higher- $M_{\mathrm{r}}$ in SDS-PAGE. Highly purified recombinant decorin induced tyrosine phosphorylation of a $170-\mathrm{kD}$ protein in a dose-dependent manner within 5 min (Fig. $3 A$ ) suggesting direct activation of the receptor. Decorin-induced activation of the $170-\mathrm{kD}$ protein comigrating with the EGF receptor was associated with a slower migrating form of p42 MAP kinase (ERK2), thereby signifying MAP kinase activation (Fig. 3, $A$ and $B)$.

Decorin binds to the EGF receptor and its activation is prevented by AG1478, a specific inhibitor of EGF receptor tyrosine kinase. To assess more directly whether decorin would bind to the EGF receptor, we incubated A431 cells with a constant amount $(\sim 20 \mathrm{ng})$ of ${ }^{125}$ I-labeled recombinant decorin and then with increasing amounts of unlabeled EGF. As shown in Fig. $4 A$, there was a significant displacement $(P>0.008)$ of the bound decorin using relatively high dosages of EGF (300 ng). The partial displacement is not surprising since decorin is known to bind to a variety of bioactive molecules. The specificity of decorin/EGF receptor interaction was further tested by additional experiments. Exogenous decorin protein core was as effective as exogenous proteoglycan in inducing phosphorylation of the $170-\mathrm{kD}$ protein (Fig. $4 \mathrm{~B}$ ), in agreement with the data obtained with the stably transfected clones discussed above. Equimolar amounts of recombinant human biglycan were essentially ineffective (Fig. $4 \mathrm{~B}$ ), indicating that the effects were specific to decorin. Fundamentally, decorin caused low levels of EGF receptor activation but prolonged activation of MAP kinase.

To assess the causal role of cell surface receptors in MAP kinase activation by decorin or EGF, we used tyrphostin AG1478, a quinazoline-specific inhibitor of the EGF receptor tyrosine kinase (27). In these experiments a concentration of AG1478 that is $1 / 50$ of that required to inhibit c-src kinase (27) effectively blocked activation of the EGF receptor kinase and MAP kinase caused by either EGF or exogenous decorin (Fig. $4 C$ ). As a further control, we found that MAP kinase activation by platelet-derived growth factor was unaffected by the same concentrations of AG1478 (data not shown). Sequential
A

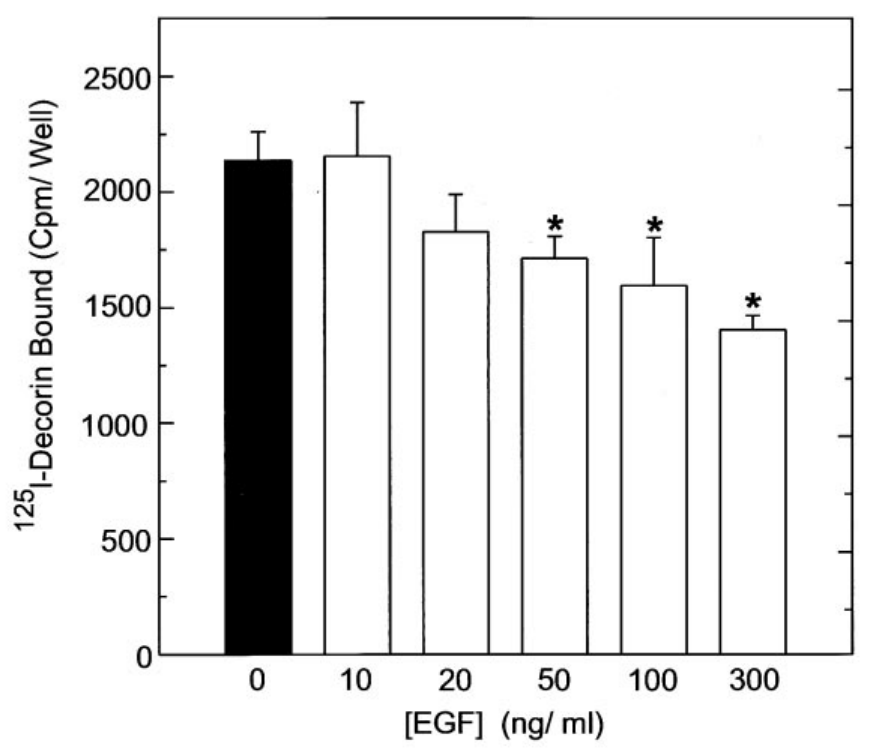

B

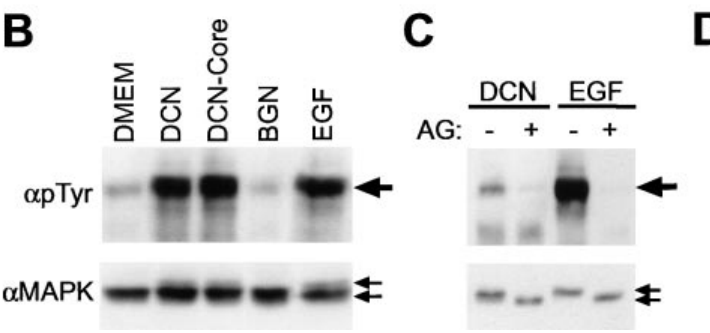

D

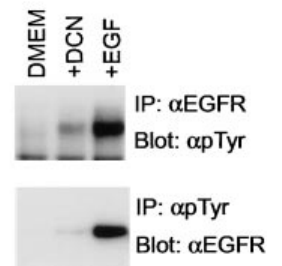

Figure 4. Decorin binds to the EGF receptor and this interaction is mediated by the protein core. $(A)$ Displacement of ${ }^{125}$ I-labeled decorin from the surface of A431 cells with increasing concentrations of cold EGF. Recombinant human decorin was labeled to high specific activity $\left(\sim 8 \times 10^{6} \mathrm{cpm} / \mathrm{mg}\right.$ ) with $\left[{ }^{125} \mathrm{I}\right] \mathrm{NaI}$ (Amersham Corp.) by the Iodo-Gen method (Pierce Chemical Co.). After a 2-d culture, A431 cells were washed twice with D-PBS, blocked with $1 \mathrm{ml}$ RPMI-1640 containing $0.2 \%$ BSA at $4^{\circ} \mathrm{C}$ for $1 \mathrm{~h}$, and incubated with $0.5 \mathrm{ml} 0.2 \%$ BSA/ RPMI1640 containing $\sim 200 \mathrm{ng}\left(1.5 \times 10^{6} \mathrm{cpm}\right){ }^{125} \mathrm{I}$-decorin with or without the indicated concentrations of EGF. After $2 \mathrm{~h}$ on ice, the wells were washed three times with cold PBS, the cells were dissolved in $1 \mathrm{ml} 1 \mathrm{M} \mathrm{NaOH}$ and the radioactivity measured in a gamma counter. Results shown are the means \pm SD of triplicate determinations. The $P$ values were determined using the paired Student's $t$ test. $* P<0.008$. (B) Decorin or its protein core $(D C N$ Core) but not biglycan $(B G N)$ induce phosphorylation of the EGF receptor and MAP kinase activation. Cells were treated with recombinant human decorin, decorin protein core, or biglycan $(100 \mu \mathrm{g} / \mathrm{ml}$ each $)$ for $5 \mathrm{~min}$ and cell lysates were subjected to immunoblotting with $\alpha \mathrm{pTyr}$ (large arrow) or $\alpha \mathrm{MAPK}$ antibodies (lower small arrows). (C) Inhibition of EGF receptor kinase blocks tyrosine phosphorylation and MAP kinase activation. Wild-type A431 cells were serum starved overnight, incubated with or without $2 \mu \mathrm{M}$ tyrphostin AG1478 $(A G)$ for $2 \mathrm{~h}$, and then incubated with DME alone or containing either $100 \mathrm{ng} / \mathrm{ml} \mathrm{EGF}$ or $50 \mu \mathrm{g} / \mathrm{ml}$ decorin $(D C N)$ for 5 min. Comparable results were obtained with an 18 h-incubation (not shown). Cell lysates were separated by SDS-PAGE, and blots were probed with the indicated antibodies. $(D)$ The tyrosine-phosphorylation induced by decorin is specific for the EGF receptor as determined by sequential immunoprecipitation $(I P)$ and immunoblotting (Blot) using antisera directed toward either EGF receptor $(\alpha E G F R)$ or phosphotyrosine residues $(\alpha p T y r)$ as indicated. 


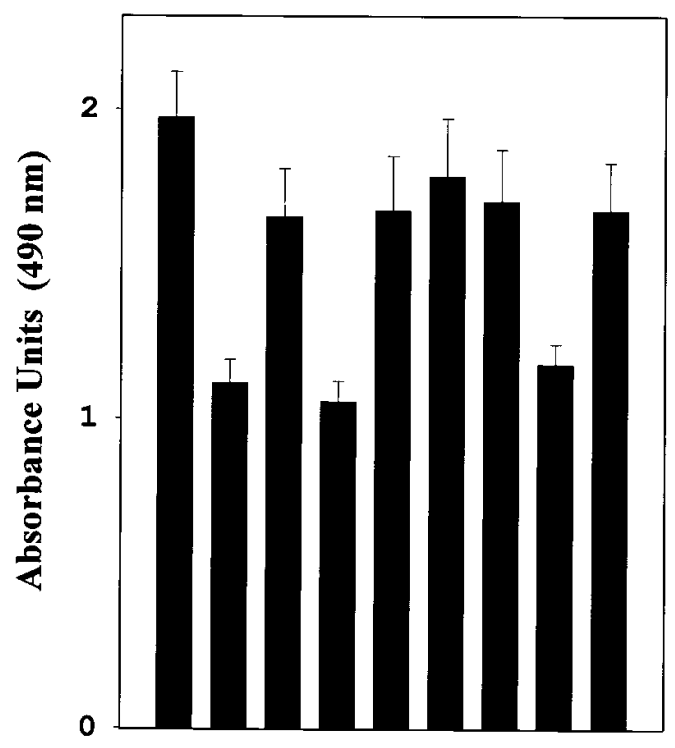

Decorin -++----

$\Delta$ Decorin --+++--

Biglycan - - - ++--

$\mathrm{EGF}--->+$

AG1478 - -++-+-+

Figure 5. The tyrphostin AG1478 prevents the growth-inhibitory effects of decorin proteoglycan or protein core in wild-type A431 cells. The recombinant proteins $(100 \mu \mathrm{g} / \mathrm{ml}=\sim 1 \mu \mathrm{M})$ were added daily for $3 \mathrm{~d}$ in the presence or absence of AG1478 $(2 \mu \mathrm{M})$. To test for activity of AG1478, cells were also cultured in the presence or absence of EGF $(100 \mathrm{ng} / \mathrm{ml})$ for $24 \mathrm{~h}$ with or without AG148 as indicated. Growth was assessed by a nonradioactive cell proliferation assay (Promega Corp.). The values are the mean $\pm \mathrm{SD}(n=5)$.

immunoprecipitation with antibodies against phosphotyrosine followed by immunoblotting with antibodies against EGF receptor, or the reciprocal experiment, demonstrated that the $170-\mathrm{kD}$ protein phosphorylated in response to decorin is the EGF receptor (Fig. $4 D$ ). This finding, thus, corroborates the data presented above (Fig. $4 A$ ).

To determine whether the decorin-induced growth suppression was mediated, at least in part, through the EGF receptor pathway, we grew A431 cells in the presence or absence of exogenous decorin or $\Delta$ decorin with or without $2 \mu \mathrm{M}$ AG1478. The results clearly showed that the growth inhibitory activity of decorin and $\Delta$ decorin could be significantly blocked by the tyrphostin (Fig. 5).

Decorin causes phosphorylation of EGF receptor, MAP kinase activation, and p21 induction in cells of diverse histogenetic background. To confirm that decorin was indeed interacting specifically with the EGF receptor, we tested additional cell lines that either lacked the EGF receptor (AGS gastric carcinoma cells) or that expressed unusually high levels $(\sim 4 \times$ $10^{6} / \mathrm{cell}$ ) of the receptors (HNSCC head and neck carcinoma cells). We also tested murine NIH3T3 fibroblasts (CO12 cells) which had been transfected with the human EGF receptor cDNA $\left(\sim 4 \times 10^{5}\right.$ receptors/cell $)$ and compared those with their wild-type counterparts which express very low levels of
EGF receptor (19). As expected for a decorin-EGF receptor interaction, decorin induced a MAP kinase shift in all the cell lines in which EGF receptor phosphorylation was observed (LTRb2, CO12, and HNSCC), but not in the AGS cells, which exhibited no response to EGF (Fig. $6 A$ ). The induced levels of p21 correlated well with the EGF receptor phosphorylation and MAP kinase activation in the responsive cells (Fig. $6 B$ ). Additional cell lines, previously shown to be responsive to ectopic expression of decorin (17), were tested for p21 induction and AG1478 block and compared to the A431 parental cells.

A

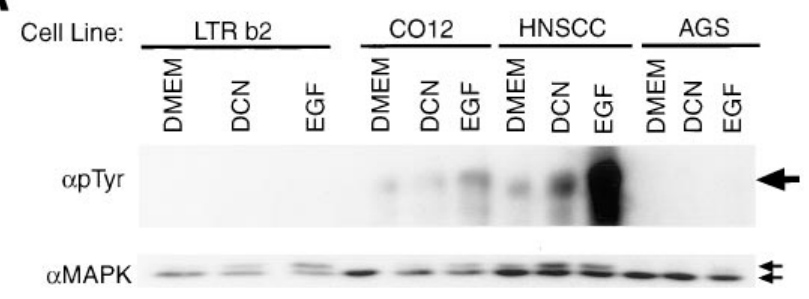

B

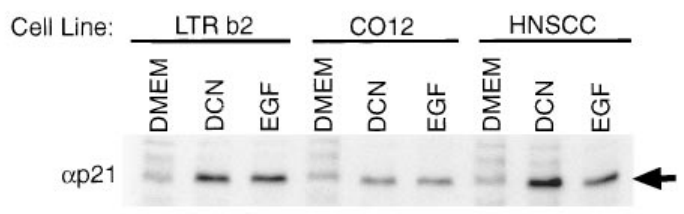

C

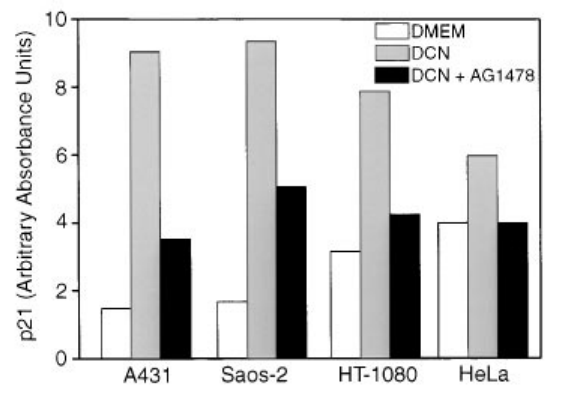

Figure 6. Decorin causes phosphorylation of the EGF receptor, MAP kinase activation, and $\mathrm{p} 21$ induction in cell lines of diverse histogenetic background. ( $A$ ) LTR b2 and CO12 are NIH-3T3 cells transfected with pLTR2 vector only ( LTR b2) or overexpressing the normal human EGF receptor (CO12) (19). HNSCC is a human squamous cell carcinoma cell line which overexpresses the human EGF receptor, and AGS is a human gastric adenocarcinoma cell line which shows no response to EGF. Cell lines were serum starved overnight before addition of $50 \mu \mathrm{g} / \mathrm{ml}$ decorin $(D C N)$ or $100 \mathrm{ng} / \mathrm{ml} \mathrm{EGF}$. Cell lysates were separated by SDS-PAGE, and blots were probed with $(A)$ antiphosphotyrosine antibody $(\alpha \mathrm{pTyr})$, anti-panERK antibody $(\alpha M A P K)$, or $(B)$ anti-p21 antibody $(\alpha p 21)$. (C) Wild-type A431, Saos-2 osteosarcoma, HT-1080 fibrosarcoma, and HeLa cervical squamous carcinoma cells were serum starved overnight with or without $2 \mu \mathrm{M}$ tyrphostin AG1478, then incubated with DME alone or with either $100 \mathrm{ng} / \mathrm{ml}$ EGF or $50 \mu \mathrm{g} / \mathrm{ml}$ decorin $(D C N)$ in the presence or absence of AG1478 for $18 \mathrm{~h}$. Immunoblot levels of endogenous $\mathrm{p} 21$ protein were quantified by laser scanning densitometry as described before (17). 
In all the cells, including Saos-2 osteosarcoma, HT-1080 fibrosarcoma and HeLa cervical carcinoma cells, decorin-dependent induction of endogenous p21 was partially or totally blocked by AG1478 (Fig. 6 C). Notably, the signal transducers and activators of transcription, STAT1 and STAT3, have been implicated in the induction of p21 by EGF in some cell lines (28). However, we observed STAT1 activation in only some of the cell lines in which decorin induced p21 (unpublished observations), in contrast to the ubiquitous activation of MAP kinase, suggesting a role for STAT proteins in p21 induction in only certain cell types. We conclude that EGF receptor is a site at which decorin initiates a signaling cascade that leads to induction of endogenous p21 and ultimately to growth arrest.

\section{Discussion}

The finding that EGF receptor is phosphorylated in A431 cells in response to exogenous decorin or its protein core is the first observation linking a secreted proteoglycan to a growth factor receptor and a protracted activation of the MAP kinase cascade. It is well established that not only growth factors, but also divalent cations and cationic polypeptides can increase tyrosine kinase activity of the EGF receptor and cause aggregation of its intracytoplasmic domain (29). A three-dimensional model of decorin (30) predicts an arch-shaped molecule with ample surface suitable for specific interactions with proteins such as the collagen triple helix and perhaps cell surface receptors. Because the activation of EGF receptor-MAP kinase pathway occurred within $5 \mathrm{~min}$, it is unlikely that decorin interacted with any other molecules, i.e., growth factor(s) synthesized by the cells that could indirectly mediate these effects. Indeed, decorin binds TGF- $\beta$ (31), but this growth-inhibitory cytokine binds to its own receptors, and it is not known to induce tyrosine phosphorylation of the EGF receptor.

While modulation of the EGF receptor kinase activity and substrate specificity by antibodies to extracellular domains of the receptors (32) or by activation of other receptor pathways (33) have been shown, this is the first demonstration of a direct signaling effect of an extracellular matrix proteoglycan. Moreover, the ability of micromolar concentrations of tyrphostin AG1478, which is highly specific for the EGF receptor (27) to block the tyrosine phosphorylation and downstream MAP kinase activation induced by decorin implicates direct activation of the EGF receptor tyrosine kinase itself. Indeed, we observed partial, albeit significant, inhibition of ${ }^{125}$ I-labeled decorin binding to the A431 cells by exogenous EGF, consistent with a direct interaction. The partial displacement suggests that decorin and EGF interact with distinct subdomains of the EGF receptor, but may be due to the interaction of decorin with other cell surface molecules. Moreover, our results clearly showed that the growth-inhibitory activity of decorin and $\Delta$ decorin are significantly blocked by the tyrphostin AG1478. While we cannot exclude the possibility that decorin may bind to other receptors that transactivate the EGF receptor, it is clear that the activity of the EGF receptor is required for the growth-suppressive effects of decorin.

Initially identified as a downstream mediator of wild-type p53 function and a potent inhibitor of CDK activities $(14,15)$ as well as a gene highly expressed during senescence (16), p21 has since been shown to be regulated by p53-independent mechanisms $(34,35)$. The induction of $\mathrm{p} 21$ by a variety of growth factors including EGF $(24,36)$ appears to be somewhat contradictory. However, it has been recognized that p21 contributes universally to the inhibition of the cell cycle progression by acting as a buffer whose levels dictate the threshold kinase activity necessary for progression through the cell cycle, and can also act as an adaptor protein to assemble and program kinase complexes for specific functions (37-39). Thus, transient or cyclical activation may lead to cell cycle progression whereas protracted p21 induction, as in the case of decorin, would lead to growth suppression. The fact that decorin is preferentially bound to collagen type I and that polymerized collagen inhibits smooth muscle cell proliferation by upregulating CDK inhibitors such as p27 and, to a lesser extent, p21 (40), further strengthens the concept that the extracellular matrix can significantly modulate the cell cycle. Adhesion-dependent cell cycle progression is yet another regulatory mechanism through which the matrix exerts its action as suspended cells fail to activate CDK activity and are associated with induction of the CDK inhibitors p27 and p21 (41).

As decorin is highly expressed by the host connective tissue stroma surrounding growing neoplasms it is possible that decorin may represent an important defense mechanism designed to counterbalance the invasiveness of cancer cells. We propose that decorin has a dual function in vivo, that is, decorin may act as a key regulator of matrix assembly and cellular growth. By interacting with fibrillar collagens and other molecules involved in inflammation and angiogenesis, such as $\mathrm{C} 1 \mathrm{q}$ or thrombospondin, decorin would modulate matrix assembly thereby influencing the microenvironment of the tumor stroma. On the other hand, by directly interacting with tumor cell receptors, such as the EGF receptor, decorin would influence the outcome of abnormal cell proliferation. Conceivably, decorin could contribute to either suppress the local growth of tumor cells, and thus be an active molecule in inhibiting tumor progression, or participate in tumor dormancy, i.e., by keeping tumor cells in a quiescent state. Our studies offer a plausible molecular explanation for these biological effects of decorin and further predict that the ability of epithelial cells to respond to mitogenic stimuli via surface receptor(s) may be regulated, at least in part, by a member of the small leucine-rich proteoglycan gene family.

\section{Acknowledgments}

We thank M. Höök, and K. Somers for providing precious biological reagents.

This work was supported by National Institutes of Health (NIH) grants RO1 CA39481 and RO1 CA47282 (R.V. Iozzo), RO1 CA51903 and RO1 CA53149 (A.J. Wong), R29 AR42320 (D.M. Mann), and RO1 AR42826 (D.J. McQuillan). D.K. Moscatello was supported by NIH training grant 5T32-CA09678.

\section{References}

1. Iozzo, R.V., and A.D. Murdoch. 1996. Proteoglycans of the extracellular environment: clues from the gene and protein side offer novel perspectives in molecular diversity and function. FASEB J. 10:598-614.

2. Krusius, T., and E. Ruoslahti. 1986. Primary structure of an extracellular matrix proteoglycan core protein deduced from cloned cDNA. Proc. Natl. Acad. Sci. USA. 83:7683-7687.

3. Day, A.A., C.I. McQuillan, J.D. Termine, and M.R. Young. 1987. Molecular cloning and sequence analysis of the cDNA for small proteoglycan II of bovine bone. Biochem. J. 248:801-805.

4. Fisher, L.W., J.D. Termine, and M.F. Young. 1989. Deduced protein sequence of bone small proteoglycan I (biglycan) shows homology with proteoglycan II (decorin) and several nonconnective tissue proteins in a variety of 
species. J. Biol. Chem. 264:4571-4576.

5. Iozzo, R.V. 1997. The family of the small leucine-rich proteoglycans: key regulators of matrix assembly and cellular growth. Crit. Rev. Biochem. Mol. Biol. 32:141-174.

6. Toole, B.P., and D.A. Lowther. 1968. The effect of chondroitin sulphateprotein in the formation of collagen fibrils in vitro. Biochem. J. 109:857-866.

7. Vogel, K.G., M. Paulsson, and D. Heinegård. 1984. Specific inhibition of type I and type II collagen fibrillogenesis by the small proteoglycan of tendon. Biochem. J. 223:587-597.

8. Danielson, K.G., H. Baribault, D.F. Holmes, H. Graham, K.E. Kadler, and R.V. Iozzo. 1997. Targeted disruption of decorin leads to abnormal collagen fibril morphology and skin fragility. J. Cell Biol. 136:729-743.

9. Adany, R., R. Heimer, B. Caterson, J.M. Sorrell, and R.V. Iozzo. 1990. Altered expression of chondroitin sulfate proteoglycan in the stroma of human colon carcinoma. Hypomethylation of PG-40 gene correlates with increased PG-40 content and mRNA levels. J. Biol. Chem. 265:11389-11396.

10. Yamaguchi, Y., D.M. Mann, and E. Ruoslahti. 1990. Negative regulation of transforming growth factor- $\beta$ by the proteoglycan decorin. Nature. 346: 281-284

11. Isaka, Y., D.K. Brees, K. Ikegaya, Y. Kaneda, E. Imai, N.A. Noble, and W.A. Border. 1996. Gene therapy by skeletal muscle expression of decorin prevents fibrotic disease in rat kidney. Nature Med. 2:418-423.

12. Santra, M., T. Skorski, B. Calabretta, E.C. Lattime, and R.V. Iozzo. 1995. De novo decorin gene expression suppresses the malignant phenotype in human colon cancer cells. Proc. Natl. Acad. Sci. USA. 92:7016-7020.

13. De Luca, A., M. Santra, A. Baldi, A. Giordano, and R.V. Iozzo. 1996. Decorin-induced growth suppression is associated with upregulation of p21, an inhibitor of cyclin-dependent kinases. J. Biol. Chem. 271:18961-18965.

14. Harper, J.W., G.R. Adami, N. Wei, K. Keyomarsi, and S.J. Elledge. 1993. The p21 Cdk-interacting protein Cip1 is a potent inhibitor of G1 cyclindependent kinases. Cell. 75:805-816.

15. El-Deiry, W.S., T. Tokino, V.E. Velculescu, D.B. Levy, R. Parsons, J.M. Trent, D. Lin, W.E. Mercer, K.W. Kinzler, and B. Vogelstein. 1993. WAF1, a potential mediator of p53 tumor suppression. Cell. 75:817-825.

16. Noda, A., Y. Ning, S.F. Venable, O.M. Pereira-Smith, and J.R. Smith. 1994. Cloning of senescent cell-derived inhibitors of DNA synthesis using an expression screen. Exp. Cell Res. 211:90-98.

17. Santra, M., D.M. Mann, E.W. Mercer, T. Skorski, B. Calabretta, and R.V. Iozzo. 1997. Ectopic expression of decorin protein core causes a generalized growth suppression in neoplastic cells of various histogenetic origin and requires endogenous p21, an inhibitor of cyclin-dependent kinases. J. Clin. Invest. 100:149-157.

18. Waldman, T., K.W. Kinzler, and B. Vogelstein. 1995. p21 is necessary for $\mathrm{p} 53$-mediated $\mathrm{G}_{1}$ arrest in human cancer cells. Cancer Res. 55:5187-5190.

19. Moscatello, D.K., R.B. Montgomery, P. Sundareshan, H. McDanel, M.Y. Wong, and A.J. Wong. 1996. Transformation and altered signal transduction by a naturally occurring mutant EGF receptor. Oncogene. 13:85-96.

20. Mann, D.M., Y. Yamaguchi, M.A. Bourdon, and E. Ruoslahti. 1990. Analysis of glycosaminoglycan substitution in decorin by site-directed mutagenesis. J. Biol. Chem. 265:5317-5323.

21. Hocking, A.M., R.A. Strugnell, P. Ramamurthy, and D.J. McQuillan. 1996. Eukaryotic expression of recombinant biglycan. Post-translational processing and the importance of secondary structure for biological activity. $J$. Biol. Chem. 271:19571-19577.

22. Ramamurthy, P., A.M. Hocking, and D.J. McQuillan. 1996. Recombinant decorin glycoforms. Purification and structure. J. Biol. Chem. 271:19578-
19584

23. Barnes, D.W. 1982. Epidermal growth factor inhibits growth of A431 human epidermoid carcinoma in serum-free cell culture. J. Cell Biol. 93:1-4.

24. Fan, Z., Y. Lu, X. Wu, A. DeBlasio, A. Koff, and J. Mendelsohn. 1995.

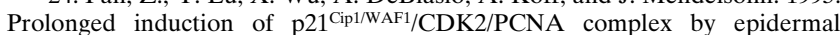
growth factor receptor activation mediates ligand-induced A431 cell growth inhibition. J. Cell Biol. 131:235-242.

25. Schlesinger, J., and A. Ullrich. 1992. Growth factor signaling by receptor tyrosine kinases. Neuron. 9:383-391.

26. Seger, R., and E.G. Krebs. 1995. The MAPK signaling cascade. FASEB J. 9:726-735.

27. Levitzki, A., and A. Gazit. 1995. Tyrosine kinase inhibition: an approach to drug development. Science. 267:1782-1788.

28. Chin, Y.E., M. Kitagawa, W.-C.S. Su, Z.-H. You, Y. Iwamoto, and X.-Y. Fu. 1996. Cell growth arrest and induction of cyclin-dependent kinase inhibitor $\mathrm{p} 21^{\mathrm{WAF} 1 / \mathrm{CIP} 1}$ mediated by STAT1. Science. 272:719-722

29. Mohammadi, M., A. Honegger, A. Sorokin, A. Ullrich, J. Schlessinger, and D.R. Hurwitz. 1993. Aggregation-induced activation of the epidermal growth factor receptor protein tyrosine kinase. Biochemistry. 32:8742-8748.

30. Weber, I.T., R.W. Harrison, and R.V. Iozzo. 1996. Model structure of decorin and implications for collagen fibrillogenesis. J. Biol. Chem. 271:3176731770 .

31. Border, W.A., N.A. Noble, T. Yamamoto, J.R. Harper, Y. Yamaguchi, M.D. Pierschbacher, and E. Ruoslahti. 1992. Natural inhibitor of transforming growth factor- $\beta$ protects against scarring in experimental kidney disease. $\mathrm{Na}$ ture. 360:361-364.

32. Defize, L.H.K., W.H. Moolenaar, P.T. van der Saag, and S.W. de Laat. 1986. Dissociation of cellular responses to epidermal growth factor using antireceptor monoclonal antibodies. EMBO J. 5:1187-1192.

33. Daub, H., F.U. Weiss, C. Wallasch, and A. Ullrich. 1996. Role of transactivation of the EGF receptor in signaling by G-protein-coupled receptors. Nature. 379:557-560.

34. Michieli, P., M. Chedid, D. Lin, J.H. Pierce, W.E. Mercer, and D. Givol 1994. Induction of WAF1/CIP1 by a p53-independent pathway. Cancer Res. 54 3391-3395.

35. Datto, M.B., Y. Li, J.F. Panus, D.J. Howe, Y. Xiong, and X. Wang. 1995. Transforming growth factor $\beta$ induces the cyclin-dependent kinase inhibito p21 through a p53-independent mechanism. Proc. Natl. Acad. Sci. USA. 92: 5545-5549.

36. Liu, Y., J.L. Martindale, M. Gorospe, and N.J. Holbrook. 1996. Regulation of $\mathrm{p} 21^{\mathrm{WAF} 1 / \mathrm{CIP} 1}$ expression through mitogen-activated protein kinase signaling pathway. Cancer Res. 56:31-35.

37. Harper, J.W., S.J. Elledge, K. Keyomarsi, B. Dynlacht, L.-H. Tsai, P. Zhang, S. Dobrowolski, C. Bai, L. Connell-Crowley, E. Swindell, et al. 1995. Inhibition of cyclin-dependent kinases by p21. Mol. Biol. Cell 6:387-400.

38. Elledge, S.J., J. Winston, and J.W. Harper. 1996. A question of balance: the role of cyclin-kinase inhibitors in development and tumorigenesis. Trends Cell Biol. 6:388-392

39. LaBaer, J., M.D. Garrett, L.F. Stevenson, J.M. Slingerland, C. Sandhu, H.S. Chou, A. Fattaey, and E. Harlow. 1997. New functional activities for the p21 family of CDK inhibitors. Genes \& Dev. 11:847-862.

40. Koyama, H., E.W. Raines, K.E. Bornfeldt, J.M. Roberts, and R. Ross. 1996. Fibrillar collagen inhibits arterial smooth muscle proliferation through regulation of Cdk2 inhibitors. Cell. 87:1069-1078.

41. Assoian, R.K. 1997. Anchorage-dependent cell cycle progression. J. Cell Biol. 136:1-4. 